\title{
Proximity loggers on amphibious mammals: a new method to study social relations in their terrestrial habitat
}

\author{
Kristine Meise $^{1, *}$, Oliver Krüger ${ }^{1}$, Paolo Piedrahita ${ }^{1}$, Achim Mueller ${ }^{2}$, \\ Fritz Trillmich ${ }^{1}$
}

${ }^{1}$ Department of Behavioural Biology and Animal Behaviour, and ${ }^{2}$ Electronic Workshop, Faculty of Biology, Bielefeld University, 33615 Bielefeld, Germany

\begin{abstract}
Amphibious mammal species alternate between foraging at sea and attendance on land. Due to thermoregulatory requirements, they often haul out during the night, making social interactions difficult to observe. We tested the suitability of UHF-proximity loggers for assessing social relationships among Galápagos sea lions Zalophus wollebaeki. To survive periods at sea, proximity loggers were embedded in epoxy. Automatic downloads to receiving stations rendered logger recovery unnecessary. Encounters were logged within a range of $10 \mathrm{~m}$. Logs provided information about interacting individuals as well as time and duration of encounters. 'Received signal strength indicator' values correlated with distance, but were influenced by antenna angle and environmental factors. Laboratory tests and validation in the field demonstrated that the spatial resolution corresponded to $2 \mathrm{~m}$. Data needed to be corrected, as single encounters were recorded as multiple logs and reciprocity of loggings between animals was not always achieved. Digital data correlated with observational data, but associations were 4 times more likely to be detected using proximity loggers. Data revealed that non-territorial males frequently associated for extended periods of time, especially during the night and even outside the study colony. The modified proximity logger system proves an excellent tool to determine social structure in situations where direct observation is limited.
\end{abstract}

KEY WORDS: Amphibious species $\cdot$ Proximity logger $\cdot$ Social structure

\section{INTRODUCTION}

Interactions among individuals shape the social organization of a group. The social structure itself influences population processes such as mate choice, information transfer, disease transmission or population genetics (e.g. Rendell \& Whitehead 2001, Böhm et al. 2008, Andrews et al. 2010). As frequency and intensity of social interactions may vary with regard to environmental cues, as well as individual attributes (e.g. sex or age, Wolf et al. 2007, Vander Wal et al. 2012), detailed information about the development and maintenance of individual social relation- ships is vital to understand the underlying processes in animal groups.

Relationships among pairs of individuals are usually determined by analysing observations of affiliative and agonistic social interactions. As interactions may occur rarely, associations are often used to describe social relationships as a surrogate measure of the probability that individuals will interact (Whitehead 2008). Depending on the observability of individuals, data collected regarding associations could be sparse, and may only represent a biased snapshot of the real social structure. In the wild, factors like vegetation density or evasive behaviour can greatly 
reduce the number of relevant observations, decreasing the potential for detecting social structure. Equally challenging is data collection in large animal groups, where hundreds of individuals use the same space, and hence following a single individual is almost impossible.

The development of biologging technologies has enabled data collection in species for which adequate numbers of observations are difficult to obtain. Radio telemetry, GPS devices (Schauber et al. 2007, Handcock et al. 2009), passive integrated transponder tags (Garroway \& Broders 2007) or satellite transmitters (Andrews 1998) provide improved results, e.g. with regard to movement patterns (Cooke et al. 2004). However, the spatial resolution of these devices does not allow the determination of close-range encounters between individuals, which are important for drawing conclusions about social interactions (D'Eon et al. 2002, Hansen \& Riggs 2008). Automatic VHF receiver stations enable triangulating the position of individuals and estimating distance between neighbours. However, information about encounters is limited to areas where receiving stations are set up, making them inappropriate for highly mobile species.

Proximity loggers provide a new tool to investigate different aspects of social behaviour, such as preferential associations and mating behaviour, parentoffspring conflict or inter-species interactions, particularly of wild species. These transceivers emit signals with a unique ID code, whilst simultaneously listening for ID pulses within receiving range. Proximity loggers have been used to investigate social interactions in a variety of species such as brushtail possums, raccoons, badgers, cattle, Tasmanian devils and European rabbits (Ji et al. 2005, Prange et al. 2006, Swain \& Bishop-Hurley 2007, Böhm et al. 2009, Hamede et al. 2009, Marsh et al. 2011a,b, Drewe et al. 2012). While testing the general applicability of proximity loggers in field studies, these publications deal with possible pathways of disease transmission, or general aspects of a species' social behaviour. The main limitation is that the loggers needed to be recovered in order to access data; this often proves difficult in wild animals. Here, we present data on a new proximity logging system developed by the Washington Encounternet Project, which allows data to be automatically downloaded to base stations (Mennill et al. 2012, Rutz et al. 2012), thus rendering the recovery of loggers unnecessary. We adapted the system to investigate social relations of amphibious mammals during the time spent ashore. While transceiver systems based on underwater acoustic tags have been applied to investigate interactions in the marine environment (Cooke et al. 2011, Lidgard et al. 2012, Hayes et al. 2013), this is the first study to test the suitability of proximity loggers to examine social behaviour of amphibious mammals in their terrestrial habitat.

Amphibious mammals spend a large amount of time in the water to forage. However, their social behaviour is often associated with extensive use of terrestrial habitat. Most pinnipeds form impressive breeding colonies with hundreds or thousands of individuals whose social structure at first sight appears rather chaotic. Galápagos sea lions Zalophus wollebaeki offer an excellent opportunity to study social relationships as they use their colonies yearround. In daylight, social interactions can easily be observed in the colony. However, certain groups of individuals, such as non-territorial males, often avoid colonies during the day to minimize exposure to the heat of the day while simultaneously avoiding aggressive encounters with more competitive males. During the night, these males come ashore and often gather in groups outside the main breeding areas (Wolf et al. 2005). However, in the dark, identification of individuals is unreliable and observations disturb the animals. Thus, observational data regarding nocturnal associations cannot be obtained. To address this problem, we tested the applicability of proximity loggers in our study system. We present a workable design and settings of proximity loggers for use in amphibious species. Issues with proximity loggers that are known to influence results in previous studies, such as broken contacts and the antenna angle (Prange et al. 2006, Drewe et al. 2012), were tested in the laboratory to assess their influence on field data. We suggest how to deal with such problems, and report the comparison of behavioural observations in the field to the digital dataset obtained by deploying proximity recorders on 23 adult males, thus validating the accuracy and functionality of the digital proximity recording method.

\section{MATERIALS AND METHODS}

This study was conducted during the reproductive season in 2011 (September to December) on Caamaño $\left(0^{\circ} 45^{\prime} \mathrm{S}, 90^{\circ} 16^{\prime} \mathrm{W}\right)$, an island $300 \mathrm{~m}$ in diameter in the centre of the Galápagos archipelago. The study site harbours one of the largest colonies of Galápagos sea lions. We conducted 2 to 3 daily resight rounds (between 05:00 and 18:00 h), noting the presence of each male identified from numbered tags, permanent characteristics or bleach marks. In 
total, we observed 227 individually identified adult males ( $\geq 5$ yr old; Pörschmann et al. 2010). In addition to the ID of a focal male, we recorded the ID of its closest associates. Associates were defined as animals lying within $10 \mathrm{~m}$ of each other. Accurate distance estimations were ensured by $10 \mathrm{~m}$ marks positioned in the inland habitat while permanent $20 \mathrm{~m}$ site marks were used along the shore line. Further, adult body length, corresponding to approximately $2 \mathrm{~m}$, could be used in estimating distances between individuals.

Proximity loggers (see below for details) were deployed on 23 non-territorial males $(\sim 10 \%$ of the males observed each season). Study animals had a mean \pm SD mass of $73 \pm 16.8 \mathrm{~kg}$, and a mean body length of $158.7 \pm 10.9 \mathrm{~cm}$. They were captured using hoop nets (R. Lohmann Tailoring; Jeglinsky et al. 2012) and briefly restrained manually. Loggers were glued onto neoprene, fixed to a piece of mesh using cable ties and attached to the fur of the animals using a fast-drying epoxy (Araldite 2012, Huntsmann Advanced Materials). Instruments were recovered by recapturing the animals $48.6 \pm 11.6 \mathrm{~d}$ after deployment, and loggers, as well as the neoprene and mesh, glued to the fur were removed (Horning \& Trillmich 1997, Jeglinski et al. 2012). The epoxy stayed on the animals only until they moulted.

\section{Proximity loggers}

We used the Encounternet system produced by the Washington Encounternet Project (www.encounternet.net), initially developed to investigate social interactions among birds. It consists of 3 elements. Proximity loggers record encounters between individuals. Base stations automatically download data from loggers. They also interact with loggers within $25 \mathrm{~m}$, thus providing information about the presence of individuals in certain areas. Master nodes attached to directional Yagi antennas are used to program proximity loggers and base stations and download data from both. Thus, settings can be changed and data can be downloaded independent of recovery of the loggers.

Proximity loggers are UHF transceivers consisting of a transmitting and a receiving unit. Every logger broadcasts a unique ID pulse at $433 \mathrm{MHz}$ radio frequency while simultaneously receiving ID codes from other devices. Whenever 2 proximity loggers are within receiving range of each other, information about this encounter is recorded and stored in the memory of the encountering loggers. A real-time clock logs information about start and end time, thus measuring the duration of an encounter. The 're- ceived signal strength indicator' (RSSI) value for each ID pulse indicates the distance to the source of an incoming signal.

Each proximity logger was fitted with a $16.5 \mathrm{~cm}$ silver-plated copper-wire antenna (1/4 wavelength) and a 2/3 A lithium battery (3 V, $1200 \mathrm{mAh}$ ) and embedded in epoxy (Seno Gießharz 4046, Bürklin) to insure waterproofing and protection against pressure. To minimize the size of the loggers, the antenna was coiled (size: $25 \times 25 \times 10 \mathrm{~mm}$ ). The logger was positioned between the antenna and the battery, leaving $15 \mathrm{~mm}$ between the logger and the battery to avoid interferences. Finally, tags were polished to achieve a cylindrical, streamlined form (size: $90 \times$ $35 \times 20$ mm, weight: 65-70 g, Fig. 1).

Proximity loggers were programmed to broadcast unique ID pulses every $10 \mathrm{~s}$ to optimize battery life span (calculated to last at least $3 \mathrm{mo}$ ). Encounters among loggers lasted until the distance between 2 loggers exceeded the detection range (approx. $10 \mathrm{~m}$ ), and/or the receiving unit could not detect the transmitter for more than $40 \mathrm{~s}$. After this period, the encounter information was stored in the loggers' memory space. Base stations were positioned on beaches where animals frequently haul out and downloaded data when loggers were within receiving range (approximately $25 \mathrm{~m}$ ).

\section{Validation under controlled conditions}

We tested the accuracy of the proximity loggers before taking them into the field. RSSI values can be used to calculate the distance between encountering loggers. To validate this for the presented logger and antenna design, we placed 2 epoxy-embedded loggers at 1, 5 and $10 \mathrm{~m}$ distance to each other. Antennas were kept in parallel. We determined the correlation

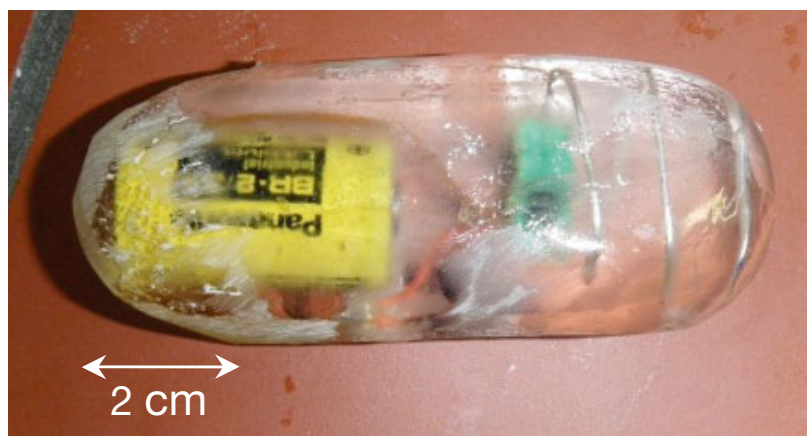

Fig. 1. Proximity logger embedded in epoxy. The coiled antenna is on the right, and the battery is on the left. The green proximity logger is positioned between the antenna and the battery 
between recorded RSSI values and the distance between loggers. Intra-logger variation in transmission strength due to hand-made antennas was assessed measuring RSSI values at $2 \mathrm{~m}$ distance.

Advantageously, the detection range of the coiled antenna was slightly lower than that of a straight antenna, ensuring that loggers only recorded close associations. Previous studies have shown that the angle between 2 antennas affects signal strength (Prange et al. 2006). We tested how the coiled antennas performed depending on the angle between them using 2 distances ( 2 and $10 \mathrm{~m}$ ). We tested 6 different antenna positions: antennas parallel to each other, facing in the same direction or in different directions; antennas at a $90^{\circ}$ angle, with the second antenna facing away from the first antenna, or pointing towards the first one; antennas at a $180^{\circ}$ angle, facing in opposite directions or facing each other. Performance was determined comparing mean RSSI values.

In previous studies, encounters have been found to break into several logs (Prange et al. 2006, Hamede et al. 2009, Drewe et al. 2012). Data have to be corrected for this phenomenon; otherwise, the interpretation of contact duration and frequency can be erroneous. We placed 2 loggers at a fixed distance of $2 \mathrm{~m}$ for $24 \mathrm{~h}$. As the maximum encounter duration was set to $30 \mathrm{~min}$, we expected 48 encounters per logger. Whenever an encounter was broken into multiple logs, we calculated the mean inter-encounter duration defined as the time between the end of the first log and the beginning of the second log.

\section{Validation of field data}

Downloads from base stations were conducted on a regular basis (every 3 to $5 \mathrm{~d}$ ) while data from loggers were retrieved ad libitum. All logs were stored in daily text files. To ensure that we were investigating socially important, rather than methodologically defined encounters in the field, we combined single logs into 1 encounter when the separation time between logs was less than the maximum inter-encounter duration determined for broken encounters in the lab. As each logger consists of a transmitting and a receiving unit, encounters should be stored on both loggers. Reciprocity was investigated using the number of encounters stored on both loggers in comparison to the number stored on only 1 logger. For mutually recorded encounters, we tested differences in the duration of encounters. Disagreement in the start times of encounters was investigated to validate the accuracy of the internal clock incorporated in each logger.
For the validation of digital data with observational data, we deleted all logs with duration of $<1$ s (following Böhm et al. 2009, Drewe et al. 2012). Removing these logs increases the accuracy of pairwise contacts (Drewe et al. 2012). Both observations and digital data had to be at least $4 \mathrm{~h}$ apart to be counted as independent events (K. Meise unpubl. data). For a direct comparison, we restricted the digital dataset to daytime encounters occurring between 05:00 and 18:00 h. We compared the number of encounters logged by each pair of proximity loggers with the observed number of encounters using permutation tests in Primer v6 (Primer-E). The comparison was used to determine how well observations represent the real social structure, and what proportion of associations was missed. We also compared frequency and duration of day- and night-time associations. Individuals that were not observed or logged by one of the base stations on a given day were considered to be associating outside the study colony.

The RSSI value provides information about distance between 2 encountering individuals. However, radio signals are affected by a variety of environmental factors such as vegetation, rocks and water bodies which absorb, refract or reflect a signal (Lee et al. 1985, Swain \& Bishop-Hurley 2007). To test whether the mean RSSI can be used to differentiate between close-range and long-range encounters, we compared logged RSSI values with estimated distances of simultaneously visually-observed encounters. Logger ID was included as a random factor in the model to avoid biases due to inter-logger variations.

\section{RESULTS}

\section{Validation under laboratory conditions}

Mean RSSI values were determined for 3 distances: 1,5 and $10 \mathrm{~m}$. We found a highly significant correlation between distance and measured RSSI values $\left(\mathrm{r}_{\mathrm{s}}=\right.$ $-0.95, \mathrm{p}<0.001)$. With increasing distance, mean RSSI values decreased at a rate of $-4.7 \mathrm{RSSI} \mathrm{m}^{-1}$. The mean \pm SD RSSI value at a distance of $2 \mathrm{~m}$ was $22.33 \pm 2.87$ $(\mathrm{N}=11)$. Maximum variation between loggers was 6.9 RSSI, which corresponds to $1.5 \mathrm{~m}$. Orientation of antennae towards each other affected signal strength (Fig. 2). Highest mean RSSI values were measured when antennae were oriented parallel to each other, independent of the direction they were facing. Signal strength was lower when antennae were positioned at a $90^{\circ}$ or $180^{\circ}$ angle $\left(\mathrm{N}=24\right.$ observations, $90^{\circ}: t=-2.60$, $\left.\mathrm{p}=0.017,180^{\circ}: t=-2.46, \mathrm{p}=0.023\right)$. Differences be- 


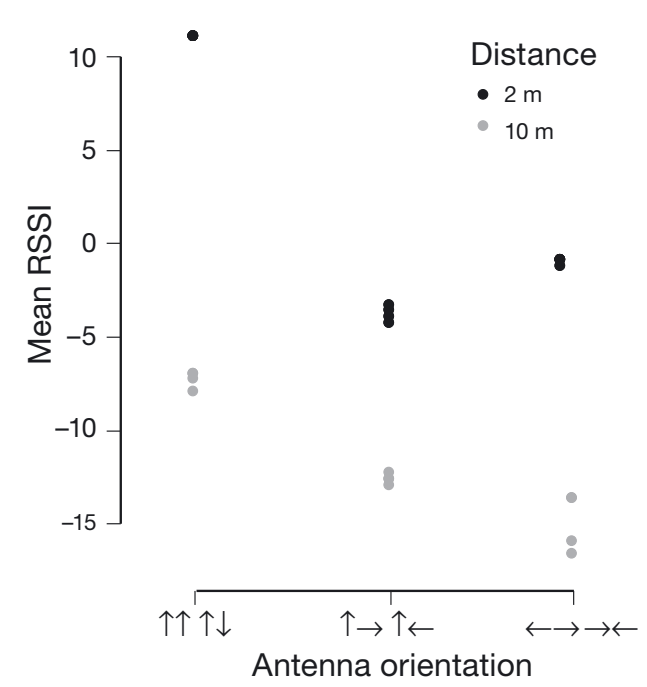

Fig. 2. Signal strength was highest for antennas oriented parallel to each other. Received signal strength indicator (RSSI) values decreased for antennas orientated at an angle of $90^{\circ}$ or $180^{\circ}$

tween RSSI values obtained for $90^{\circ}$ and $180^{\circ}$ angles were significant, but only correspond to a difference of $0.6 \mathrm{~m}$. Fig. 2 shows that the change in RSSI values is not linear for close distances (here $2 \mathrm{~m}$ ).

The laboratory test revealed that $42 \%$ of all encounters were recorded as multiple logs. Mean interencounter duration was $79 \mathrm{~s}$, while the maximum duration was 9 min $36 \mathrm{~s}$. Under field conditions (moving animals, absorption of radio waves by vegetation), we expected that continuous encounters would often break into several logs, and that the interencounter duration would be higher than the mean. We therefore used the maximum inter-encounter duration measured in the lab and combined logs less than 10 min apart into 1 encounter.

\section{Application and validation of field data}

Of the 23 deployed proximity loggers, 21 were recovered at the end of the field season. One individual lost its logger within the first $15 \mathrm{~d}$ after deployment, and data were excluded from the analysis. A second individual was not recaptured at the end of the season, but data were regularly downloaded to base stations and were therefore included in the analysis. Comparison of logs among encountering loggers revealed that the internal clock of 1 logger was not running accurately. We excluded its data from further analysis, as a validation of the records with behavioural data was not possible. The following analyses are based on 2863 single logs recorded by 21 different loggers.

\section{Reciprocal agreement}

As recent studies have found disagreements in the number and duration of contacts recorded by encountering loggers developed by Sirtrack (Drewe et al. 2012), we investigated the reciprocal agreement among pairs of Encounternet loggers. In our study, $38.5 \%(\mathrm{~N}=240)$ of all encounters were recorded by only 1 logger. A large proportion of these encounters $(38 \%)$ lasted for only $0 \mathrm{~s}$, indicating individuals passing at the edge of the receiving range. If loggers receive only one signal from an encountering logger, start and end time are the same and the duration of the loggers accordingly corresponds to 0 seconds. Excluding these 1-sided encounters reduced the disagreement in the number of contacts to $27.8 \%$. Mean difference in logged encounter duration was $24.7 \%$. It included brief encounters in which one logger recorded a duration of $0 \mathrm{~s}$, while the other logger recorded $0.12 \mathrm{~s}$. This equates to $100 \%$ difference in duration, although the difference in duration is extremely small. Excluding these data, mean temporal difference between loggers was $16.6 \%$.

We further assessed difference in the internal clocks of 2 encountering loggers. The mean difference in start time was $21.68 \mathrm{~min}$. Comparing pairwise shifts over time revealed that differences in start time increased by up to $2 \mathrm{~min}^{-1}$. This made a regular resetting of the internal clock necessary. A firmware update provided by the Encounternet project is expected to reduce this shift to a few seconds. Nevertheless, it is advisable to check data for time shifts.

\section{Validation with behavioural data}

We combined single logs $<10 \mathrm{~min}$ apart and excluded logs with a duration of $0 \mathrm{~s}$, leaving 1004 encounters. Encounters only recorded by 1 logger were duplicated and added to the dataset of the interacting logger. The term 'encounter' will be used to describe logs that were combined when $<10 \mathrm{~min}$ apart. Associations are defined as encounters lasting for $>5 \mathrm{~min}$.

Using proximity loggers, the number of recorded associations increased by $83 \%$ (Table 1) compared to associations recorded through direct observation. To assess the accuracy of the dataset, we determined how many visually observed associations were recorded by the loggers. We observed 68 associations among 21 males equipped with proximity loggers. Of these associations, 33 (48\%) were not recorded by 
Table 1. Zalophus wollebaeki. Comparison of the number of data recorded by proximity loggers and direct observations. Given are the minimum and maximum values recorded for individuals equipped with proximity loggers. Logging dramatically increased the amount of data

\begin{tabular}{|c|c|c|}
\hline & Logger & Observations \\
\hline Encounters (no. ind. ${ }^{-1}$ ) & $16-91$ & $0-40$ \\
\hline $\begin{array}{l}\text { Different individuals } \\
\text { encountered (no. ind. }{ }^{-1} \text { ) }\end{array}$ & $3-18$ & $0-11$ \\
\hline Encounter duration & $8 \mathrm{~s}$ to $8 \mathrm{~h}$ & - \\
\hline $\begin{array}{l}\text { Total no. of associations } \\
\text { recorded }\end{array}$ & 377 & 68 \\
\hline Associations (no. ind. ${ }^{-1}$ ) & $1-38$ & $0-12$ \\
\hline
\end{tabular}

the loggers. Four missed associations were due to full memory. Twenty of the remaining 29 missed associations took place at a distance of $10 \mathrm{~m}$. As observed distances were estimated, some of the missed associations might have occurred at slightly larger distances. Comparing the number of logs recorded $(\mathrm{N}=$ 9) and not recorded $(\mathrm{N}=20)$ at $10 \mathrm{~m}$ distance supports the laboratory finding that this distance represents the edge of the receiving range. Only 9 of the observed associations occurring in mid-receiving range $($ mean $=6.4 \mathrm{~m}, 13 \%$ ) were not recorded.

To assess whether observational data fit to digital data, we compared encounter matrices. We found a strong correlation between the number of observed and logged associations during the day $(\mathrm{N}=21, \mathrm{R}=$ $0.468, \mathrm{p}<0.001,999$ permutations). As expected due to the daily cycle of non-territorial males, observed data were slightly less correlated with the dataset including day- and night-time logs $(\mathrm{N}=21, \mathrm{R}=0.357$, $\mathrm{p}<0.001$ ). To rule out any effect resulting from our definition of associations, we repeated the analysis defining associations as encounters lasting $\geq 10 \mathrm{~min}$. We obtained the same result for the correlation between the number of logged and observed associations during the day $(\mathrm{N}=21, \mathrm{R}=0.347, \mathrm{p}<0.001)$ and the complete dataset including day- and night-time logs $(\mathrm{N}=21, \mathrm{R}=0.343, \mathrm{p}<0.001)$.

Data recorded by proximity loggers provided detailed information about the frequency and duration of day and night encounters. There was no significant difference in the number of associations (Wilcoxon test: $\mathrm{N}=21, V=136.5, \mathrm{p}=0.099$ ) occurring during day or night. However, animals spent more time in proximity to other individuals during the night than during the day (linear mixed-feffect model: $\mathrm{N}=21, t=2.322, \mathrm{p}=0.021$; Fig. 3 ). This was due to night-time associations lasting longer $(\mathrm{N}=21$, $t=3.620, \mathrm{p}<0.001$ ).

\section{RSSI signal strength}

To validate the use of RSSI values in estimating distance between 2 interacting loggers in the field, we analysed mutual encounters only. We found a significant correlation between mean RSSI values and distances of observed associations $\left(\mathrm{N}=16, \mathrm{r}_{\mathrm{S}}=-0.608\right.$, $\mathrm{p}<0.001$; Fig. 4). However, the variation of mean RSSI for the observed distances was high.

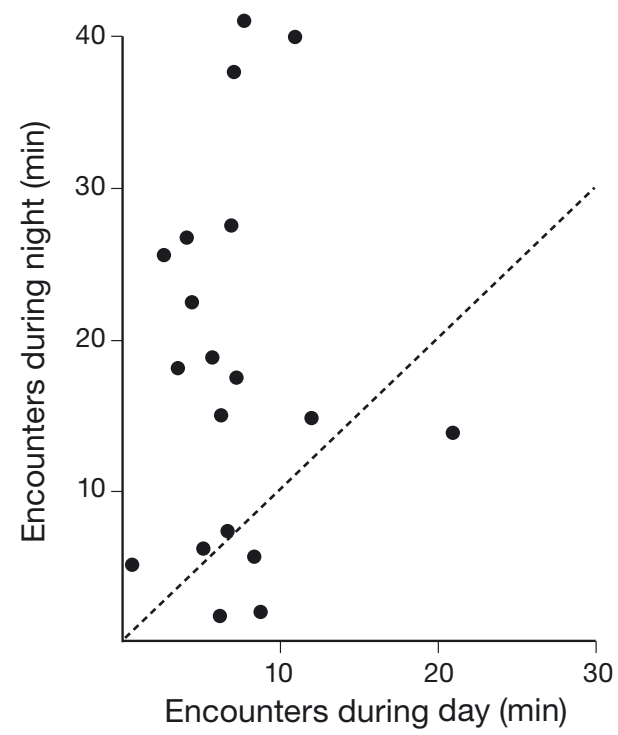

Fig. 3. Zalophus wollebaeki. Mean encounter duration during the day plotted against mean encounter duration during the night for each individual $(\mathrm{N}=21)$. Most encounters lasted longer at night than during the day

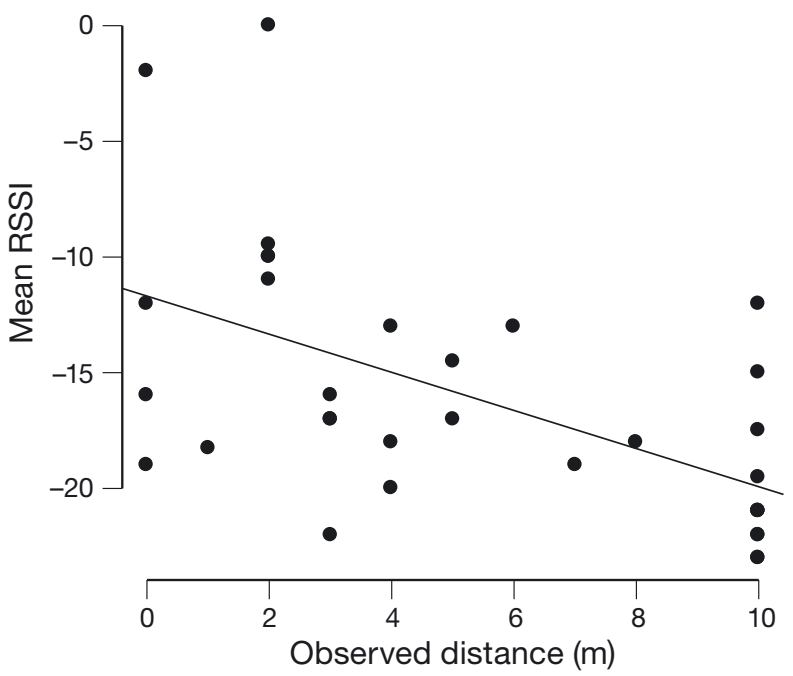

Fig. 4. Observed distance (m) correlated significantly with the mean received signal strength indicator (mean RSSI). To assess distance between interacting loggers using the mean RSSI values, the following equation was fitted: mean RSSI = $-11.668-(0.826 \times$ distance $)$ 


\section{DISCUSSION}

Species with an amphibious lifestyle are difficult to observe as they alternate between foraging in water and resting or breeding on land. Proximity loggers provide a unique opportunity to investigate individual relationships and social structure, as they enable continuous data collection of social interactions, independent of time of day, habitat structure or spatial location. This allows an accurate quantification of encounter frequencies, which is not possible to obtain from observations alone. Our results showed that the modifications needed to achieve waterproofing and pressure resistance of loggers did not influence their effectiveness in detecting interactions between pairs of individuals. However, the data obtained have to be interpreted with care. Previous studies have indicated problems with datasets recorded by proximity loggers (Prange et al. 2006, Böhm et al. 2009, Drewe et al. 2012): signal detection distances varied with antenna angles, single encounters were logged as multiple events, and non-existing identification codes were recorded ('phantom contacts'). We conducted tests under controlled conditions to estimate the impact of such errors in our modified system. The proximity loggers used in the present study provide information about received signal strength that can be used to calculate the distance between interacting loggers. Due to the coiled antenna and the embedding of the logger and antenna in epoxy resin, the receiving range of our loggers was restricted to approximately $10 \mathrm{~m}$. Highest mean RSSI values of 32 were reached when loggers were lying next to each other. Under controlled conditions, mean RSSI values decreased with a rate of $4.7 \mathrm{RSSI} \mathrm{m}^{-1}$ and can therefore be used to estimate distance between 2 encountering loggers. However, attention should be paid to a number of factors. First, distance calculated from mean RSSI values varies within a range of 2 to $3 \mathrm{~m}$, depending on the angle of the antenna (also found in Prange et al. 2006); further, mean RSSI values did not decrease linearly for different antenna angles at close distances. Second, the field trial revealed high variation in received signal strength values. This variation can be explained by intra-logger variation due to the modified antennas. Further, radio waves are affected by characteristics of the environment, behaviour of the animal or even weather conditions, all influencing the estimated distance (Böhm et al. 2009). Therefore, it is advisable to use $2 \mathrm{~m}$ categories to differentiate between close-range and long-range encounters, rather than estimate contin- uous distance values. Still, the spatial resolution is superior to comparable electronic devices such as GPS (D'Eon et al. 2002).

Continuous encounters were often recorded as multiple logs. As stated by Drewe et al. (2012), unfiltered data may lead to an overestimation of the frequency of encounters, while the duration would be underestimated. To obtain a biologically meaningful dataset, rather than one distorted by methodological artefacts, such logs have to be combined. We suggest testing the inter-encounter duration to find a suitable cut-off interval for correcting data. Phantom contacts were not observed in the present study. We cannot explain the occurrence of such contacts in previous studies, but assume that they were induced by radio waves transmitted by other systems. Our study site was quite isolated and UHF noise therefore minimal.

After appropriate filtering of data, 2 interacting loggers should provide the same information; however, complete reciprocity was lacking in our field data. Full memory space, interactions at the edge of the receiving range and behaviour of the animals affect the probability that an encounter is logged by both encountering units. Furthermore, the propagation probability of radio waves can influence reciprocity (Böhm et al. 2009). Once both loggers receive each other's signal, the actual difference in the logged encounter duration is comparably small $(17 \%)$. The higher agreement in duration, rather than the frequency of encounters, was also found in a previous study (Drewe et al. 2012). To obtain a complete dataset for each individual, data need to be checked for reciprocity.

Non-territorial male Galápagos sea lions frequently interact with other males. Although the general pattern of who is interacting with whom was similar between observational and digital data, proximity loggers provided a much more detailed dataset. The number of records increased by $83 \%$ and revealed that associations among pairs of males were more common than expected from observations. For our analysis, we concentrated on associations only. Associations lasted much longer than predicted based on male movement patterns observed during the day. The fact that males were found in proximity of each other for a certain time period (here $>5 \mathrm{~min}$ ) and repeated associations occurred among specific pairs of individuals suggests that these encounters are neutral, or even affiliative, and supports the assumption that long-term relationships do exist among non-territorial males. The longer durations during the night are likely explained by the absence of thermoregulatory problems. Unfortunately, with 
the data obtained from the proximity loggers, we cannot establish the nature of short-term encounters. An encounter occurring at a short distance and lasting for 2 min could mean that males slowly pass each other at close distance without engaging in any agonistic behaviour. The same data could be recorded if males engage in aggressive neck wrestling contests. To further understand the nature of encounters, proximity loggers could be combined with other devices such as accelerometers that may permit identification of certain types of behaviour (Naito et al. 2010, Whitney et al. 2010) or GPS to detect resting spots outside the study colony. A comparison of the digital dataset with the attendance data obtained from base stations revealed that some males frequently associate outside the study colony. This suggests that social preferences among non-territorial males go beyond shared spatial preferences.

Proximity loggers can successfully be modified to last through long-term immersion in seawater and sustain high pressure. Our experience suggests that the system needs to be validated separately for every species, as recording characteristics might vary with regard to individual behaviour and habitat features. With this proviso, proximity recorders provide a major improvement of our ability to collect data on social interactions independent of an individual's observability. The methodology can be employed to obtain not only insights into frequency and duration of social relationships among males as described here, but could also be useful to record data on social networks (Wolf et al. 2007, Whitehead 2008, Krause et al. 2009), site fidelity (Pomeroy et al. 2000), mating interactions, sexual segregation (Staniland 2005), relationships among kin within a colony (Wolf \& Trillmich 2008), preferential assortment among breeding females (Pomeroy et al. 2000), as well as fostering behaviour (Boness et al. 1998), parentoffspring conflict (Trivers 1974) or disease transmission (Böhm et al. 2008).

Acknowledgements. This study was funded by the German Research Foundation (TR 105/18-2). We are grateful for the permission from and close collaboration of the Galápagos National Park Service as well as the logistical support of the Charles Darwin Research Station. We thank J. Burt for advice when adapting proximity loggers to the marine environment. E. Kunisch and M. Zimmermann provided valuable assistance in the field.

\section{LITERATURE CITED}

Andrews RD (1998) Remotely releasable instruments for monitoring the foraging behaviour of pinnipeds. Mar Ecol Prog Ser 175:289-294
Andrews KR, Karczmarski L, Whitlow WLA, Rickards SH and others (2010) Rolling stones and stable homes: social structure, habitat diversity and population genetics of the Hawaiian spinner dolphin (Stenella longirostris). Mol Ecol 19:732-748

Böhm M, Palphramand KL, Newton-Cross G, Hutchings MR, White PCL (2008) Dynamic interactions among badgers: implications for sociality and disease transmission. J Anim Ecol 77:735-745

> Böhm M, Hutchings MR, White PCL (2009) Contact networks in a wildlife livestock host community: identifying high-risk individuals in the transmission of bovine TB among badgers and cattle. PLoS ONE 4:e5016

> Boness DJ, Craig MP, Honigman L, Austin S (1998) Fostering behavior and the effect of female density in Hawaiian monk seals, Monachus schauinslandi. J Mammal 79: 1060-1069

Cooke SJ, Hinch SG, Wikelski M, Andrews RD, Kuchel LJ, Wolcott TG, Butler PJ (2004) Biotelemetry: a mechanistic approach to ecology. Trends Ecol Evol 19:334-343

Cooke SJ, Iverson SJ, Stokesbury MJW, Hinch SG and others (2011) Ocean Tracking Network Canada: a network approach to addressing critical issues in fisheries and resource management with implications for ocean governance. Fisheries 36:583-592

D'Eon RG, Serrouya R, Smith G, Kochanny CO (2002) GPS radiotelemetry error and bias in mountainous terrain. Wildl Soc Bull 30:430-439

Drewe JA, Weber N, Carter SP, Bearhop S and others (2012) Performance of proximity loggers in recording intra and inter-species interactions: a laboratory and field-based validation study. PLoS ONE 7:e39068

Garroway CJ, Broders HG (2007) Nonrandom association patterns at northern long-eared bat maternity roots. Can J Zool 85:956-964

Hamede RK, Bashford J, McCallum H, Jones M (2009) Contact networks in a wild Tasmanian devil (Sarcophilus harrisii) population: using social network analysis to reveal seasonal variability in social behaviour and its implications for transmission of devil facial tumour disease. Ecol Lett 12:1147-1157

> Handcock RN, Swain DL, Bishop-Hurley GJ, Patison KP and others (2009) Monitoring animal behaviour and environmental interactions using wireless sensor networks, GPS collars and satellite remote sensing. Sensors (Basel) 9: 3586-3603

- Hansen MC, Riggs RA (2008) Accuracy, precision, and observation rates of global positioning system telemetry collars. J Wildl Manag 72:518-526

> Hayes SA, Teutschel NM, Michel CJ, Champagne C and others (2013) Mobile receivers: releasing the mooring to 'see' where fish go. Environ Biol Fishes 96:189-201

> Horning M, Trillmich F (1997) Ontogeny of diving behaviour in the Galápagos fur seal. Behaviour 134:1211-1257

> Jeglinski JWE, Werner C, Robinson PW, Costa DP, Trillmich F (2012) Age, body mass and environmental variation shape the foraging ontogeny of Galapagos sea lions. Mar Ecol Prog Ser 453:279-296

Ji W, White PCL, Clout MN (2005) Contact rates between possums revealed by novel proximity data loggers. J Appl Ecol 42:595-604

Krause J, Lusseau D, James R (2009) Animal social networks: an introduction. Behav Ecol Sociobiol 63:967-973

Lee JE, White GC, Garrott RA, Bartmann RA, Alldredge AW (1985) Assessing accuracy of a radio-telemetry sys- 
tem for estimating animal locations. J Wildl Manag 49: 658-663

Lidgard DC, Bowen WD, Jonsen ID, Iverson SJ (2012) Animal-borne acoustic transceivers reveal patterns of atsea associations in an upper-trophic level predator. PLoS ONE 7:e48962

Marsh MK, Hutchings MR, McLeod SR, White PCL (2011a) Spatial and temporal heterogeneities in the contact behaviour of rabbits. Behav Ecol Sociobiol 65:183-195

Marsh MK, McLeod SR, Hutchings MR, White PL (2011b) Use of proximity loggers and network analysis to quantify social interactions in free-ranging wild rabbit populations. Wildl Res 38:1-12

Mennill DJ, Doucet SM, Ward KA, Maynard DF, Otis B, Burt JM (2012) A novel digital telemetry system for tracking wild animals: a field test for studying mate choice in a lekking tropical bird. Methods Ecol Evol 3:663-672

- Naito Y, Bornemann H, Takahashi A, McIntyre T, Plötz J (2010) Fine-scale feeding behavior of Weddell seals revealed by a mandible accelerometer. Polar Sci 4: 309-316

Pomeroy PP, Twiss SD, Redman P (2000) Philopatry, site fidelity and local kin associations within grey seal breeding colonies. Ethology 106:899-919

> Pörschmann U, Trillmich F, Mueller B, Wolf JBW (2010) Male reproductive success and its behavioural correlates in a polygynous mammal, the Galápagos sea lion (Zalophus wollebaeki). Mol Ecol 19:2574-2586

Prange S, Jordan T, Hunter C, Gehrt SD (2006) New radiocollars for the detection of proximity among individuals. Wildl Soc Bull 34:1333-1344

Rendell L, Whitehead H (2001) Culture in whales and dolphins. Behav Brain Sci 24:309-324

Rutz C, Burns ZT, James R, Ismar SMH and others (2012)

Editorial responsibility: Christine Paetzold,

Oldendorf/Luhe, Germany
Automated mapping of social networks in wild birds. Curr Biol 22:R669-R671

Schauber EM, Storm DJ, Nielsen CK (2007) Effects of joint space use and group membership on contact rates among white-tailed deer. J Wildl Manag 71:155-163

Staniland I (2005) Sexual segregation in seals. In: Ruckstuhl KE, Neuhaus P (eds) Sexual segregation in vertebrates. Ecology of the two sexes. Cambridge University Press, Cambridge, p 53-73

Swain DL, Bishop-Hurley GJ (2007) Using contact logging devices to explore animal affiliations: quantifying cowcalf interactions. Appl Anim Behav Sci 102:1-11

Trivers RL (1974) Parent-offspring conflict. Am Zool 14: 249-264

- Vander Wal E, Yip H, McLoughlin PD (2012) Sex-based differences in density-dependent sociality: an experiment with a gregarious ungulate. Ecology 93:206-212

Whitehead H (2008) Analyzing animal societies: quantitative methods for vertebrate social analysis. University of Chicago Press, Chicago, IL

Whitney NM, Pratt HL Jr, Pratt TC, Carrier JC (2010) Identifying shark mating behaviour using three-dimensional acceleration loggers. Endang Species Res 10:71-82

Wolf JBW, Trillmich F (2008) Kin in space: social viscosity in a spatially and genetically substructured network. Proc R Soc Lond B Biol Sci 275:2063-2069

> Wolf JBW, Kauermann G, Trillmich F (2005) Males in the shade: habitat use and sexual segregation in the Galápagos sea lion (Zalophus californianus wollebaeki). Behav Ecol Sociobiol 59:293-302

> Wolf JBW, Mawdsley D, Trillmich F, James R (2007) Social structure in a colonial mammal: unravelling hidden structural layers and their foundations by network analysis. Anim Behav 74:1293-1302

Submitted: September 17, 2012; Accepted: January 11, 2013 Proofs received from author(s): February 21, 2013 